\title{
Assessing the Value of a Mobile Application in Fostering Ideation within a School Context
}

\author{
Gisli THORSTEINSSON ${ }^{1}$, Rosa GUNNARSDOTTIR ${ }^{2}$, Andrei NICULESCU ${ }^{3}$ \\ ${ }^{1}$ University of Iceland, \\ v/Stakkahlid, 101, Reykjavik, Iceland \\ cdt@khi.is \\ ${ }^{2}$ University of Bifröst, \\ Bifrost. 311 Borgarnes. Iceland \\ r.gunnarsd@gmail.com \\ ${ }^{3}$ Spiru Haret University, \\ 13 Ion Ghica Street, Bucharest 3, Romania \\ andreiniculescu@hotmail.com
}

\begin{abstract}
The purpose of this paper is to explore the usefulness of the mobile application NeedIT in fostering ideation and idea generation in a school context. After having been used and tested in three public schools a research was undertaken in an elementary school in order to examine the application usability from instructor and student perspectives. In order to gain an insight into the context of using the mobile application in teaching and learning, the authors examined current literature and collected data through observations, semi-structured interviews, and by observing the NeedIT underlying database. The study attempted to answer the following questions: 1) How can mobile technology be used to support students' ideation? 2) What obstacles are there in developing students' ideation within this context? 3) How can the methods be further developed or refined? 4) What are the benefits of using mobile technology for ideation in schools? The study also highlighted the importance of teaching students to differentiate between problem-needs to be independently identified by students within their home or community environment and possible solutions to be developed and evaluated in collaboration with the classroom teacher. The application has proved to be valuable for its intended use; however it needs to be further developed so that it may also be used as a medium in establishing course content based on students'homework assignments passed electronically to school. The perceived overall value of mobile technology in schools lies partly in the multifaceted capabilities associated with this modern technology and novel attempts have been made to employ its use in many different educational settings.
\end{abstract}

Keywords: ideation, problem-needs, solutions, mobile device, mobile application.

\section{Introduction}

There is a wide variety of software applications that foster idea generation. They differ essentially in their emphasis, but all are aimed at helping with problem need identification (PNI), exploration and designs. These idea generation tools intend to (1) enable the stream of ideas through brainstorming (2) stimulate the formation of an initial idea through analogical thinking, morphological analysis and synectics and (3) improve ideas. Examples may include Lateral Thinking, Scamper and Triz. Other software packages that support ideation include those that help determine target users and provide new information and techniques that support decision-making.

The mobile application NeedIT was designed to support ideation, via Tablet-PCs or mobile phones, within Innovation Education and Entrepreneur Education. As a result of several research projects focused on the pedagogy of Innovation Education (IE), the current paper puts forward a research based on NeedIT application. The main emphasis of the pedagogy is to ensure that students are better equipped to deal with their world and that they play an active part in society through innovation [12], [32]. The ideational skills developed during IE aim to encourage this aspect of students' development and thus strengthen the ability of future societies, in terms of innovation and development [28]. Ideation was identified as vital in establishing student's undertakings and in underpinning course content [12], [32]. The ideation process in these case studies was based on students' search for problems and needs in their environments, which they recorded in their inventor's notebook. As a result of the sophisticated mobile technology that is becoming an important part of young people's daily lives, in seeking information for communication and for documentation [30]. In addition, as schools do not use mobile technology in education very often, it was thought that this would be a novel and helpful 
method in identifying the educational value and functional capabilities of mobile applications within an educational context.

This paper examines the literature associated with ideation and mobile technology and then outlines the specific mobile application used for the enquiry. The authors then describe the research methodology and report the findings. Finally, they discuss the outcome and draw their conclusions.

\section{Problem-Need Identification (PNI) to Underpin Ideation}

Ideation and ideation skills are central to the formation of ideas within the process of innovation. PNI is commonly incorporated in techniques for innovative thinking [14] and is thus a significant part of ideation: it may be generally defined as a method or process that goes before problem-need solving [25]. PNI played an important role in this enquiry, as the innovation process began in the students' own environment. Part of ideation is accountable to PNI and supports an individual's competencies in resolving PNs in everyday life [33]. Identifying and defining the finding of problem-needs is a significant aspect of ideation and, sometimes, PNs are remarkably difficult to deal with. Nevertheless, solutions are often obvious, once properly analysed [14], [33].

Ideation has been defined as 'the faculty or capacity of the mind for forming ideas; the exercise of this capacity; the act of the mind by which objects of sense are apprehended and retained as objects of thought' [27], [33]. In this research, students initiated ideation inside school and as homework, within their own environment. There was a focus on the identification of problem-needs, which was seen as the foundation for the generation of ideas during courses. PNI was also identified as a significant source of information, enabling the work of both students and teachers. Moreover, it allowed the teacher to establish the content of the course and understand the thoughts and undertakings of students [33].

During ideation, individuals must search for many new solutions to problems: this has been referred to as a divergent style [36]. Ideation incorporates both typical and exceptional suggestions, which may lead to the random occurrence of unusual knowledge and many ideas. The majority of researchers support group brainstorming in backing up ideation; however, some have advised that individual brainstorming generates more active results than group work does [8], [17], [23].

\section{Software Applications and Mobile Technology to Support School Education}

A synthesis of the related literature demonstrates that mobile technologies are capable of supporting students' engagement in ideation within the contexts of creative, cooperative, critical and communicative learning. It is also highlighted that teachers and learners use mobile technologies to support these real-world practices [15]. The literature also emphasizes how mobile technologies are beneficial in building and enhancing creative, collaborative interactions and in supporting communities of practice. [3], [22], [27], [38] asserted the benefits of mobile technology as providing students with a shared conversation space, stating 'effective learning happens when students can converse with each other by cross-examining and sharing their accounts of the world.'

There are now various software applications available that facilitate the idea-exchange process. Research studies pertaining to electronic brainstorming techniques have indicated that electronic brainstorming (EBS) groups outperform (in terms of number of ideas generated) verbal groups and the performance difference grows as the group size grows [1], [5], [6], [7], [9], [10], [26], [35].

The ability to enter ideas anonymously in electronic brainstorming may remove evaluation apprehension and production blocking: two suspected reasons for decreased idea generation in face-to-face, verbally interactive brainstorming.

Earlier research work [4], [7], [10], [24], [35] attributed the superior performance of computer-based groups to three factors [35]. First of all, computer-mediated communication allows all group members to instantaneously enter ideas, thus reducing production blocking. Secondly, as group members can simply review the ideas of others, there are lower levels of redundant submissions, relative to no interacting nominal groups. Thirdly, as group members can easily review the ideas of others, 
there are opportunities for cognitive stimulation (i.e., synergy) and enhanced performance.

\section{The Specific Mobile Application NeedIT}

The software application NeedIT aims at fostering ideation: it enables young students to use a mobile device such as a smartphone or an android tablet to capture images of places, items or persons that spur the notion of a need or problem that needs solving. Furthermore, it enables students to collect information regarding identified problem-needs in their environment in the form of photo images, drawings, audio recordings and text. Students can also gain support from the Internet if they require further information or if their work benefits from the use of other online software applications, in terms of documenting their ideas. NeedIT automatically saves the students work in an online database that is accessible at any location as the home or the school when the students want to work further with their ideas.

Allowing a mobile method of gathering images supports a broad analysis of situations and contexts at the moment of collection and allows participants to work on their ideation where and when the collection of such images takes place. This working method supports communications and enables students to seek help from adults around them.
The diagram, in Figure 1, shows the structural design of the application. An underlying on-line database retains all the students' work carried out during the ideation process. They have both registered identified problem-needs in their environment and eventually found possible solutions. Both are shown as drawings, photos and descriptions. The solutions that have been brought to realisation inside the classroom are demonstrated as photos of models and prototypes as well as written descriptions. The screen captures show the NeedIT interface after students have had a clear image of proper settings relating to the identified problem-need with written description. One may also figure out how students can access multiple solutions they have found to solve a certain problemneed. The work is accessible from underlying database from different locations on a mobile device or computer and can be further developed. Students' homework focused on identifying problem-needs becomes the basis of the course work at school. Here the students work with solutions via realization bringing their ideas into a material form, thus making Innovation Education be aimed at finding and developing solutions.

NeedIT is password protected and as such a personal storage. When the user has logged in he/she is presented with a play button that activates the camera in the device. Below is a wireframe prototype of the app as it was
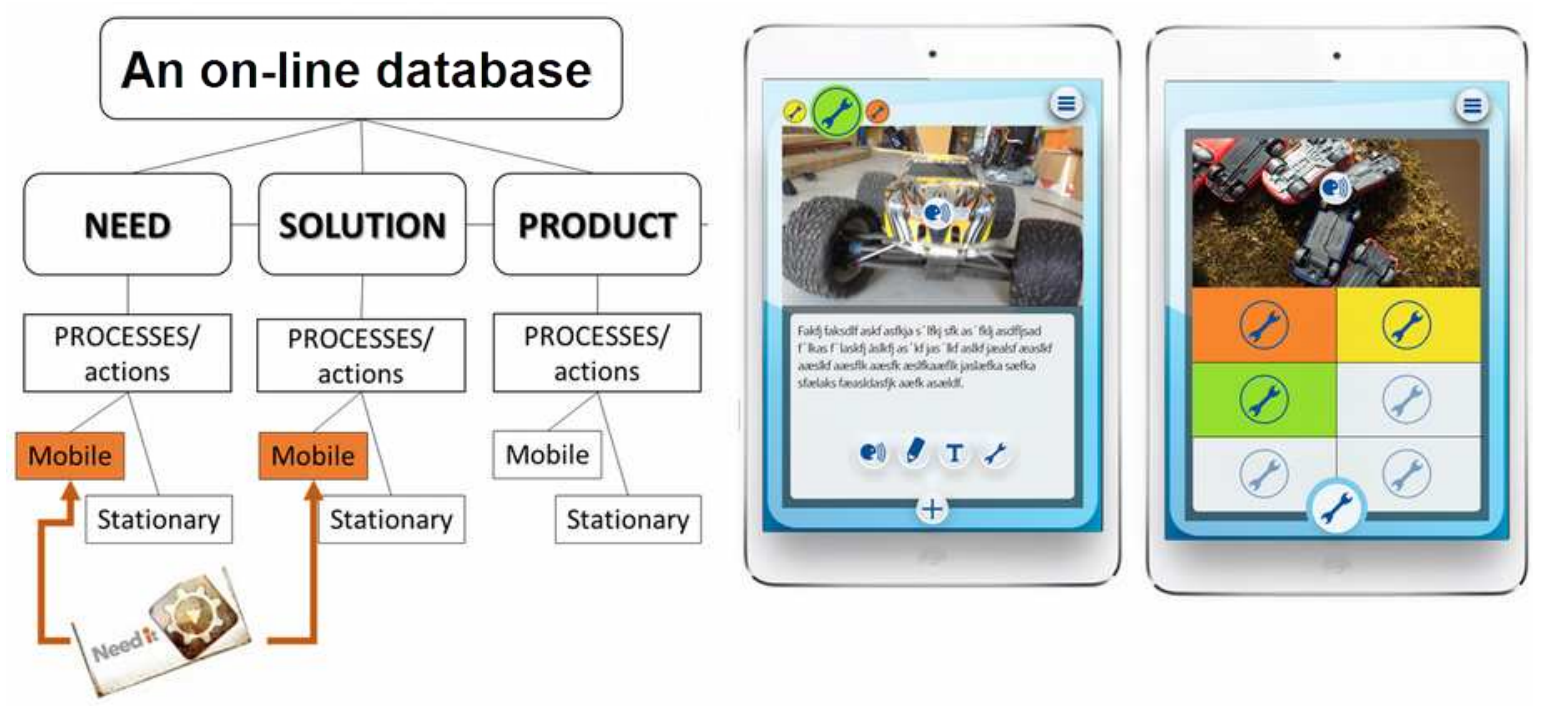

Figure 1. The architecture of the NeedIT application with examples. 
designed (Figure 2). Figure 2 shows an exemplar process of what the students can do. First is to log in and then start using the camera in the device to collect and register needs. The second step is to analyse the need either by using voice recording and drawing over the picture or writing a text on it. The last step is to register and define a solution to the problem/need.

NeedIT is written for Android 4.4 (Kit Kat) and is featured as a way of using the camera on a device to take images of the item, place or person that spurred a question or need, (identified as a mobile action above). This is stored not on the mobile device itself but on a Cloud service that enables students to do further work using the software on their local computer (identified as stationary action above). When the image is stored, one can then draw on the image for further explanation, record a voice tag or write a short analysis of the situation or need. These images can then serve as a stimulus for brainstorming, regarding solutions and inventions further into the ideation process.

\section{Research Design and Methodology}

The enquiry was based on two case studies, each consisting of a one-week summer camp course. Two teachers took the lessons, while fifteen students (ages 7-13) volunteered in the first study and twelve students (ages 9-12) partook in the second case study. The participants were shown how to use the specific application on a 10 -inch android tablet and were advised to document needs and problems they identified in their own environments. Students used the application both at home and during lessons: this enabled them to discuss their findings as a group and to brainstorm in order to establish the course content. The students learned to register problem-needs and solutions via text, photos, voice recordings and CAD. They subsequently worked with individual solutions and made models of their solutions.

The main aim of the research was to explore the possibilities surrounding the use of the NeedIT mobile application in fostering ideation among school-aged students.

The objectives were to:

1. monitor students' use of the application during ideation.

2. investigate, via current literature, the importance of the development of using mobile applications with a view to supporting ideation within a school context.

3. carry out an investigation, using interviews and an underlying database, in order to gain an insight into the context of the use of a mobile application in teaching and learning.

4. identify any barriers in using the application in the nurturing of ideation, in order to develop it further.

The research questions were:

1. How can mobile technology be used to support students' ideation?

2. What obstacles are there in developing students' ideation in this context?

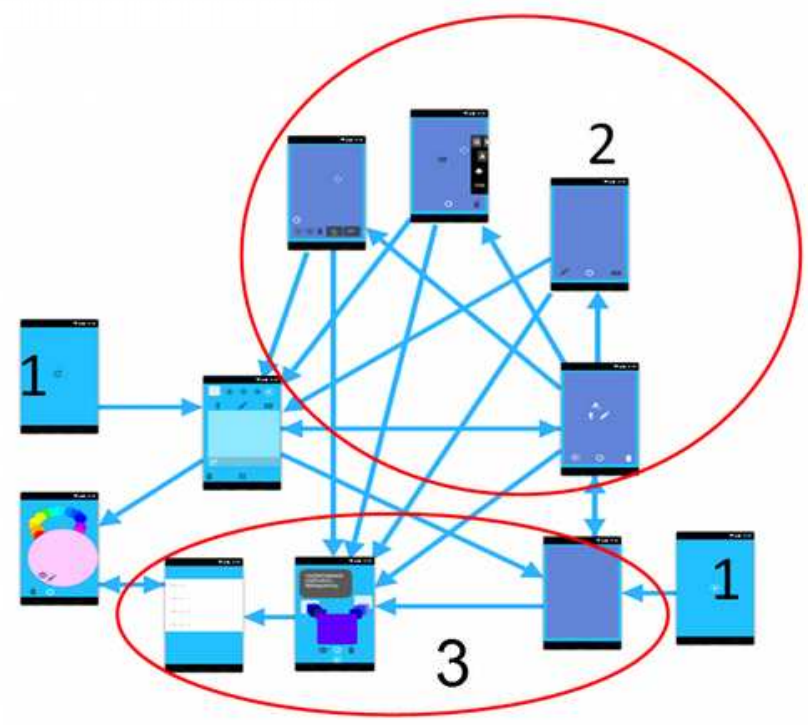

1. Login for NeedIT/SolveIT

2. Analysis tools

- Voice recording

- Drawing

- Text writing

3. Solution definition

Figure 2. A wireframe structure of the NeedIT app. 
3. How can the methods be further developed or refined?

4. What are the benefits of using mobile technology for ideation in schools?

The research was undertaken in three stages, using a phenomenographic approach. It aimed to interpret, examine and understand [2] students' competences in implementing NeedIT applications to support their ideation skills. The results of the study are presented as an account of all the imaginable ideas students had around a phenomenon.

The first stage of the research incorporated a review of students' work, through an examination of an underlying database containing their ideas. The second stage consisted of interviews with students and teachers, in order to determine further understanding of some areas of their activities. Semi-structured interviews were utilised to examine issues surrounding the students' use of the NeedIT software and its impact upon their coursework. The teachers kept logbooks during the courses and took photos of any activities. They also kept records of the various webbased software applications that students used to enable their ideation work.

\section{Findings}

The following findings were established through the interviews, the data from, the application underlying database and observations (logbooks):

- The use of mobile technology can easily distract students from their learning tasks.

- The NeedIT app allowed students to begin the identification of problem needs and helped them to personalise their undertakings.

- NeedIT enabled students to generate the content of the course.

- The students had to be taught to differentiate between problems-needs and solutions.

- The students easily learned to use the application, largely through their own experiences.

- Internet connection provided students with the possibility of working further with solutions.

- Social media was not distracting, due to the young age of the students.
- The tablet-pc was more useful in the home context than the teachers had imagined.

- The mobile application is not creative in itself, but can support ideation.

- The NeedIT app was more of a distraction for the youngest students.

- The app should just be used to collect problem-needs, in the support of further work.

- Preference for a simple interface.

- There are many web-based applications on a tablet that enable students' ideation work.

- It is important to create a specific platform for developing solutions.

\section{Discussion}

It was noted that older students became easily distracted from their course tasks when using mobile devices inside school; this could have been due to the fact that they had easy access to interesting websites and online games. The youngest students became distracted when using the tablets, which may have been a result of the novelty factor. Despite this, the use of mobile devices brings multi-channel learning support to ideation activities inside the classroom. [37] claimed that schools are no longer places where learners go to gain knowledge for use in the outside world. Moreover, he asserted that learning should take place both in the student's environment and inside school. [11] and [16] outlined the educational value of the social contexts in which learning takes place, with their research supported by [3], [22], [ 27] and [38] agreed with the benefits of mobile technology in supporting collaborative learning and communities of practise.

NeedIT was designed to help students collate problem-needs to underpin further work; consequently, in the first case study, students were asked to identify problem-needs. However, when they returned, they had documented solution on their devices. Thus, they needed to be taught to differentiate between problem-needs and solutions prior to the second case study. The PNI is the preliminary state of the ideation innovation process and NeedIT is aimed at underpinning students' undertakings inside the classroom. According to [14], [20] and [25] the identification and definition of problem-needs 
is a significant step in training students to solve problems, find solutions and enables collaboration via brainstorming.

In the second case study, the NeedIT application assisted students in identifying problem-needs, helping them to personalise their undertakings and establish course content. However, this was dependent upon the teachers' respect for the students' autonomy and freedom to make their own choices, with regards to their projects. [12] and [34] identified social associations between students' environment and the school as vital and associated to social constructivism [9], [18], [31], [34].

Students easily learned to use the technology; however, it was noted that the first interface was too complicated for their ideation activities. Thus, the application had to be made simpler. According to Mayhew [21] userinterface design is a matter of compromise and trade-off: the interface must have powerful functionality, but it should be simple, dependable and clear. [16] informed that a well-designed interface enables learning and underlines the importance of consistency across all aspects of its design.

NeedIT is not creative in itself, but it supports students' ideation in general. It was more useful in the home context than the teachers had imagined, as it enabled a link between the students' environment and the school. The internet connection was a bit distracting; nonetheless, it could be used as an offline tool in getting students more focused on course tasks. [13] clearly indicated the need for setting limitations and establishing 'tech-etiquette' for the use of wireless technologies in schools, in order to avoid pupil distraction.

The provision of an Internet connection and Android tablets allowed students to further develop their solutions. Using different webbased software applications accessible from their tablet-PCs also enabled their ideation work. However, it was proved that the application was not in itself an appropriate tool in developing solutions as it was just aimed for problem-need identification. Future work will be dedicated to develop a window-based platform that will be known as InnoEdt. This application will enable students to develop solutions using different online applications in relation to Google Chrome.

\section{Conclusion}

The use of NeedIT supported students in identifying problem-needs and activated their idea generation. It also helped to establish course content. However, this was dependent upon teachers supporting students' autonomy [12], [20], [25], [32], [33].

To avoid students becoming distracted by the novelty of devices and the Internet, it is important to use the application offline, in terms of identifying and recording problem-needs [14]. However, it helps to work online on a different platform when developing solutions, enabling the use of different online applications [19].

The use of modern mobile devices and NeedIT provides multi-channel learning support within the classroom [37] and enables learning support in the students' social contexts [8], [11], [15], [17], [23], [36].

It is important to teach students' to differentiate between problem-needs and solutions before they begin using the application for ideation. This supports their ideation activities inside the classroom and enables the teacher to establish collaboration via brainstorming [25], [36].

The research highlights the importance of designing simple but powerful tools to readily enable students' work: this will help them to learn about and utilise the technology in ideation activities [16], [21]. Programmers must also consider that applications and devices are not creative, but are aimed at supporting ideation.

The use of mobile devices in Icelandic and Romanian elementary schools is still in its infancy; thus, it is important to investigate how these devices can support the development of ideation skills in schools, both in terms of the development of the pedagogy and the technology.

\section{REFERENCES}

1. AIKEN, M., M. RIGGS, Using a Group Decision Support System for Creativity. Journal of Creative Behaviour, vol. 27(1), 1993, pp. 28-35.

2. COHEN, L., L. MANION, K. MORRISON, Research Methods in Education $\left(5^{\text {th }} \mathrm{ed}\right.$.) Taylor \& Francis e-Library, UK, 2005.

3. COLLEY, J., G. STEAD, Mobile Learning = Collaboration. Proc. of mLearn 2004: Mobile learning anytime everywhere. 
London: Learning and Skills Development Agency, 2004, pp. 57-58.

4. CONNOLLY, T., L. M. JESSUP, J. S. VALACICH, Effects of Anonymity and Evaluative Tone on Idea Generation in Computer-mediated Groups. Management Science, vol. 36(6), 1990, pp. 689-703.

5. DE VREEDE, G. J., R. O. BRIGGS, R. REITER-PALMON, Exploring Asynchronous Brainstorming in Large Groups: A Field Comparison of Serial and Parallel. Subgroups. Human Factors, vol. 52(2), 2010, pp. 189-202.

6. DE VREEDE, G. J., G. DICKSON, Using GSS to Design Organizational Processes and Information Systems: An Action Research Study on Collaborative Business Engineering. Group Decision and Negotiation, vol. 9(2), 2000, pp. 161-183.

7. DENNIS, A. R., J. S. VALACHICH, Computer Brainstorming: More Heads are Better Than One. Journal of Applied Psychology, vol. 78(1), 1993, pp. 531-537.

8. DUGOSH, K. L., P. B. PAULUS, Cognitive and Social Comparison Processes in Brainstorming. Journal of Experimental Social Psychology, Vol. 41(1), 2005, pp. 313-320.

9. EDWARDS, A. Researching Pedagogy: A Sociocultural Agenda. Pedagogy, Culture and Society, vol. 9(2), 2001, pp. 161-186.

10. GALLUPE, R. B., W. H. COOPER, M. GRISÉ, L. M. BASTIANUTTI, Blocking Electronic Brainstorms. J. of Applied Psychology, vol. 79(1), 1994, pp. 77-86.

11. GREDLER, M. E. Learning and Instruction: Theory into Practice $\left(3^{\text {rd }} \mathrm{ed}\right)$. NJ: Prentice-Hall, 1997.

12. GUNNARSDOTTIR, R., Research in Innovation Education: Socio-Cultural Methods for Research and Analysis for Defining Educational Phenomenon. Visions on Sloyd and Sloyd Education. Techno Series: Research in Sloyd Education and crafts science B, vol. 10(1), 2001, pp. 65-104.

13. HEMBROOKE, H., G. GAY, The Laptop and the Lecture: The Effects of Multitasking in Learning Environments. Journal of Computing in Higher Education. vol. 15(1), 2003.
14. HILEY, A., A. COLLIS, J. A. WILSON, Through the Wardrobe: a Generic Platform to Foster the Evolution of Creative Problem-solving Skills. International Conference on Creativity or Conformity: Building Cultures of Creativity in Higher Education, Cardiff, Wales, UK, 2007.

15. JACKSON, R., J. KARP, E. PATRICK, A. THROWER, Social Constructivism Vignette. Retrieved (21 Jan. 2015) from http://projects.coe.uga.edu/epltt/index.php? title=Social_Constructivism.

16. KHAN, K., ZULAIKA, Z. ALI, N. PHILIP, G. DEANE, A. SAHAI, An Intelligent Water Droplet-based Evaluation of Health Oriented Distance Learning. Journal of Advances in Information Technology, vol. 4(2), 2013, pp. 91-100.

17. LAREY, T. S., P. B. PAULUS, Group Preference and Convergent Tendencies in Small Groups: A Content Analysis of Group Brainstorming Performance. Creativity Research Journal, vol. 12, No. 3, 1999, pp. 175-185.

18. LEHTONEN, M., T. PAGE, G. THORSTEINSSON, Simulations and Virtual Realities as Modern Tools in Technology Education: Looking for Proper Pedagogical Models, in Multidisciplinary Approaches to Learning. Helsinki University Press, 2005.

19. LOVELESS, A., Literature Review in Creativity, New Technologies and Learning. Report 4: A report for NESTA Futurelab. Retrieved (20 Jan. 2015) from http://www.nestafuturelab.org/research/revi ews/cr01.htm.

20. LUCKIN, R., J. AKASS, J. COOK, P. DAY, N. ECCLESFIELD, F. GARNETT, M. GOULD, T. HAMILTON, A. WHITWORTH, A. Learner-Generated Contexts: Sustainable Learning Pathways Through Open Content. OpenLearn 2007 - Researching Open Content in Education, Milton Keynes: Open University, 2007, pp. 30-31.

21. MAYHEW, D. J. The Usability Engineering Lifecycle: a Practioner's Handbook for User Interface Design. Morgan Kaufmann Publishers, San Francisco, 1999. 
22. NAISMITH, L., P. LONSDALE, G. VAVOULA, M. N. SHARPLES, Futurelab Report 11: Literature Review in Mobile Technologies and Learning. Bristol, UK: NESTA Futurelab. Retrieved (21 Jan. 2015) http:/www.nestafuturelab.org/research/revi ews/reviews_11_and12/11_01.htm.

23. PAulus, P. B., K. L. DugOSH, M. T. DZINDOLET, H. COSKUN, V. L. PUTMAN, Social and Cognitive Influences in Group Brainstorming: Predicting Production Gains and Losses. European Review of Social Psychology, vol. 12(1), 2002, pp. 299-325.

24. PINSONNEAULT, A., H. BARKI, R. B. GALLUPE, N. HOPPEN, Electronic Brainstorming: The Illusion of Productivity. Information Systems Research, vol. 10(2), 1999, pp. 110-133.

25. RUNCO, M. A., G. DOW, Problem Finding. in Runco, M. A. and Pritzker, S.R., Encl. of Creativity, vol. 2(1). Academic Press, San Diego, 1999, pp. 433-435.

26. SHEPHERD, M. M., R. O. BRIGGS, B. A. REINIG, J. YEN, J. F. NUNAMAKER, Social Comparison to Improve Electronic Brainstorming. Journal of MIS, vol. 12(3), 1996, pp. 155-170.

27. STEAD, G., Moving Mobile into the Mainstream. Proceedings of mLearn 2005. Retrieved (21 Jan. 2015) from http://www. mlearn.org.za/CD/papers/Stead.pdf

28. THE MINISTRY OF EDUCATION. The Icelandic National Curriculum 1999. Reykjavik: Ministry of Education, 1999.

29. The Webster Dictionary, 2005, Retrieved (21 Jan. 2015) from http://www.m-w.com/.

30. THORSTEINSSON, G. T. PAGE, User Attachment to Smartphones and Design Guidelines. International Journal of Mobile Learning and Organisation. Vol. 8(3/4), 2014, pp. 201-215.

31. THORSTEINSSON, G. The Innovation Project in Icelandic Grade schools. Development of Technology Education Conference-98. University of Jyväskylä. The principles and Practice of teaching, vol. 33(1), 1998, pp. 303-323.
32. THORSTEINSSON, G., DENTON, H. G., Ideation in a Virtual Learning Environment: A Pilot Project from Iceland in Innovation Education. In Norman, E.W.L., Spendlove, D. and OwenJackson, G. (Eds), The Design and Technology Association International Research Conference book 2006. Telford, July 2006, The Design and Technology Association, Wellesbourne, pp. 155-164.

33. THORSTEINSSON, G., NICULESCU, A. Using Mobile Technology for Problem Need Identification in School-aged Children Environment. Studies in Informatics and Control, vol. 21(4), 2012, pp. 431-438.

34. THORSTEINSSON, G., T. PAGE, A. NICULESCU, Using Virtual Reality for Developing Design Communication, Studies in Informatics and Control, vol. 19(1), 2010, pp. 93-106.

35. VALACICH, J. S., A. R. DENNIS, T. CONNOLLY, Idea Generation in Computer-based Groups: A New Ending to an Old Story. Org. behaviour and human decision processes, vol. 57(3), pp. 448-467. Exploring the Use of a Virtual Reality Learning Environment to Support Innovation Education in Iceland. 1994, p. 374.

36. VIDAL, R. V. V. FRI\&FRO - et fremtidsvaksted, IMM, DTU (in Danish) unpublished manuscript, Denmark, 2006, p. 22.

37. WENGER, E. Communities of Practice a Brief Introduction. Retrieved (21 Jan. 2014) http://www.ewenger.com/theory/communiti es_of_practice_intro_WRD.doc.

38. ZURITA, G., NUSSBAUM, M., SHARPLES, M. Encouraging Face-toFace Collaborative Learning through the Use of Hand-held Computers in the Classroom. Proceedings of Mobile HCI 2003. Italy: Springer-Verlag, pp. 193-208. 